\title{
Sex differences on a group test of figural aftereffects'
}

GOLdA KOFfMAN AND ALEXAMDER W. PRESSEY

UNIVERSITY OF MANITOBA, CANADA

This study assessed the validity of employing a rating scale on a group basis to measure visual figural aftereffects. Measures of presence and vividness of aftereffects were obtained from five pattems used to induce distortion. The results showed that there was a high incidence of reports of distortion in the expected direction and that men reported more figural aftereffects and rated each aftereffect as more vivid than women.

Prolonged inspection of one figure (I-figure) produces distortions in apparent size, shape, position, and luminosity of a slightly different figure ( $T$-figure). Such phenomenal distortions are called flgural aftereffects (FAEs).

Two major research strategies have been adopted in an attempt to provide a satisfactory explanation of FAEs. The first, employed by a majority of investigators, has been to determine the manner in which the FAE is affected by stimulus variables. The second approach has focussed upon organismic variables and is typified by attempts that have been made to relate FAEs to braindamage (Klein \& Krech, 1952), schizophrenia (Wertheimer, 1954), mental retardation (Spitz \& Blackman, 1959) and dimensions of personality such as introversion-extraversion (Eysenck, 1955) and fleld dependenceindependence (Immergluck, 1966). The results of investigations guided by the "'individual-difference" approach are encouraging, not only from the standpoint of clarifying the phenomenon of FAE, but also from the point of view of relating perception to enduring personality patterns.

One problem facing investigators concerned with individual differences in FAEs is that often large samples of Ss are required. Since tests of FAEs traditionally have been administered individually, extensive research becomes impractical. The purpose of the present study was to assess the validity of employing a rating scale on a group administered basis to obtain measurements of a FAE. Two indices of validity were chosen, viz., presence of phenomenal distortion in the expected direction and sex of the $\mathrm{S}$. The latter criterion was chosen because of incidental, but persistent, reports that women exhibit smaller FAEs than men when measurements are obtained by the method of adjustment or a variation of the method of constant stimuli (Kelm²; Paul, 1965; Pressey, 1965; Wertheimer, 1954). A confirmation of similar sex differences in the present study would attest to the validity of employing a rating scale on a group basis to measure a FAE.

\section{Method}

Five different patterns for inducing and testing for a FAE were drawn with ink on 8.5- $x$ 11.0-in. sheets of heavy white paper. The fixation- (F-) point for each I-figure was located at the center of the sheet, 2.5 in. from the top. The F-points for the $T$-figures were centered at a distance of $\mathbf{2 . 5}$ in. from the bottom of the sheet. The $T$-figure of the first pattern (A) consisted of two vertical lines, each .7 in. long, located .2 in. directly above and below the F-point. The I-figure was identical to the $T$-figure except that the line above the F-point was .063 in. to the left of the position occupled by the T-line and the I-line on the bottom was .063 in. to the right of the $\mathrm{T}-\mathrm{line}$.

The T-figure of Pattern B consisted of two equal circles whose centers were 1 in. to the left and right of the F-point. The diameter of each circle was .8 in. The I-figures were also two circles whose centers were 1 in. to the left and right of the F-point but the diameter of the circle on the left was 1 in. and that of the circle on the right was .6 in. Pattern $C$ was similar to Pattern A except that the I- and T-lines were horizontally oriented and the I-line on the left was lower than the I-line on the right. Pattern D was similar to B except that the I-circle on the left was smaller than the circle on the right. Finally, Pattern E was the reverse of $\mathrm{C}$ with the I-line on the left being higher than the I-line on the right.

For each pattern a questionnaire was employed to determine whether distortion occurred and to assess the vividness of this distortion. Thus, for example, for pattern D S was asked "to check which of the following occurred in the $T$-circles: right circle larger; left circle larger; no apparent difference." In addition, he was asked to rate the vividness of his experience on a linear scale divided into five equal parts. The low end of the scale was anchored with the number 1 and the words "just noticeable" and the upper end of the scale was anchored with the number 5 and the words "extremely vivid."

Ss were 77 men and 58 women enrolled in an introductory psychology course at the University of Manitoba and these were tested in groups of approximately 20. Each $\mathbf{S}$ was seated before a partitioned section of a table and a brief introduction to the phenomenon of FAEs was given. I- and T-figures similar to Pattern B (except that squares were used) were drawn in crude form on a chalkboard. Ss were told that they would be presented with similar patterns and that they were 
to fixate on the F-point of the figure on top then, on a signal, switch their gaze to the figure at the bottom. They were told that the second figure would appear distorted but no mention was made of the direction or type of distortion that was expected. Ss were also informed that some figures produce stronger effects than others and that the objective of the study was to determine which patterns yielded the largest degree of distortion. The I-time for each figure was $45 \mathrm{sec}$ and the intertrial interval was approximately $120 \mathrm{sec}$.

\section{Results and Discussion}

Two types of scoring procedures were employed. One was based on discrete responses of distortion in the expected direction and the second was based on the rating of vividness of distortion. Separate analyses were carried out on the two types of scores.

In the first analysis, each S's score was determined by summing the number of reports of distortion in the expected direction. This method yielded scores ranging from 0 to 5 . Frequency distributions, shown in Fig. 1, were plotted separately for men and women. Two facts are clearly evident from Fig. 1. First, most of the Ss reported between 3 and 4 occurrences of a FAE which is well above the 1.67 expected on a chance basis. Second, the distributions for men and women are different; on the whole, women reported fewer FAEs than did men. The value of $t$ for the difference between means was $2.56(p<.02)$.

In the second analysis, a score for each $\mathrm{S}$ was obtained by summing the ratings of vividness for all reports of FAEs in the expected direction. This procedure allowed scores to range from 0 to 25. Frequency distributions once again showed that women perceived a smaller FAE than men. This is not an

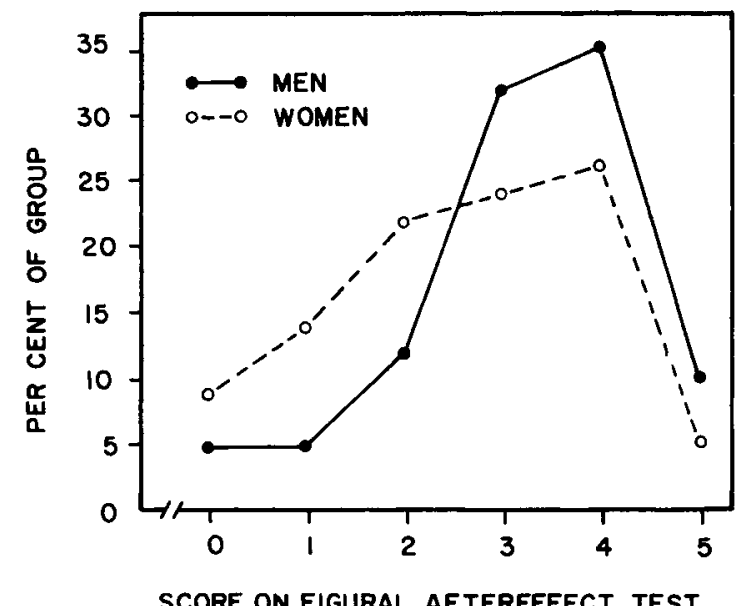

Fig. 1. Frequency distributions of scores on a group test of visual figural aftereffects.

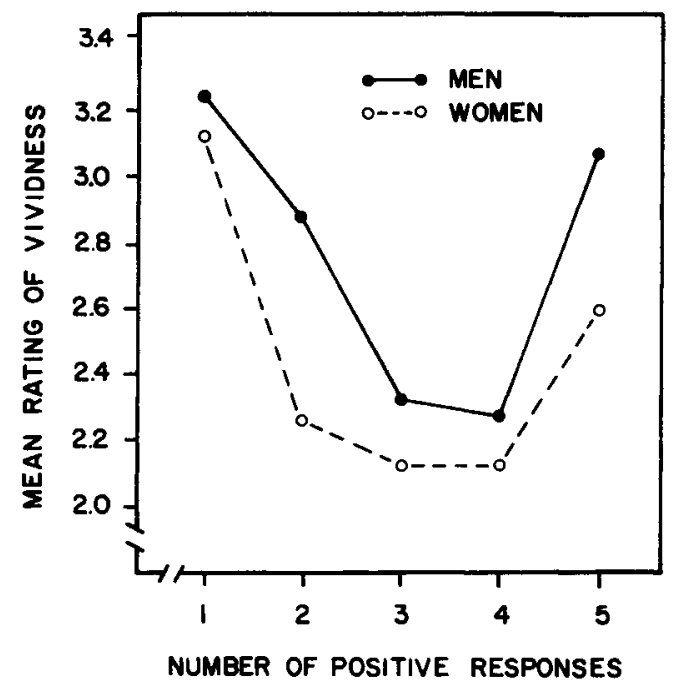

Fig. 2. Mean rating of vividness as a function of number of reports of distortion in the expected direction.

unexpected result since the ratings were based in part on the first measure of discrete responses. Therefore, in order to determine whether the ratings per se exhibited a sex difference, the mean rating for each positive response was calculated separately for men and women. The results, shown in Fig. 2, indicate that regardless of the number of reports of FAEs, men tended to rate each FAE as more vivid than women.

In conclusion, the present study confirms the presence of sex differences on tests of FAEs, and thus, the use of a rating scale on a group basis appears to be a valid method of measuring FAEs.

\section{References}

Eysenck, H. J. Cortical inhibition, figural after-effect, and theory of personality. J. abnorm. soc. Psychol.. 1955, 51, 94-106. Immergluck, $\mathbf{L}$. Visual figural after-effects and field dependence. Psychon. Sci., 1966, 4, 219-220.

Klein, G. S., \& Krech, D. Cortical conductivity in the brain injured. J. Pers., 1952, $21,118-148$.

Paul, S. K. A note on sex differences in figural aftereffects. Psychological Studies, 1965, 10, 143-144.

Pressey, A. W. The distance gradient in visual and kinesthetic figural after-effects. Unpublished doctoral dissertation, University of Alberta, 1965.

Spitz, H. H., \& Blackman, L. S. A comparison of mental retardates and normals on visual figural after-effects and reversible figures. J. abnorm. soc. Psychol., 1959, 58, 105-110.

Wertheimer, $M$. The differential satiability of schizophrenic and normal subjects: A test of a deduction from the theory of figural after-effects. J. gen. Psychol., 1954, 51, 291-299.

\section{Notes}

1. This research was supported in part by the National Research Council of Canada (APA-177).

2. Personal communication, 1964. 